\title{
Use of cerebrospinal fluid drawn at pneumo- encephalography in the study of monoamine metabolism in man
}

\author{
E. GARELIS ${ }^{1}$ AND T. L. SOURKES ${ }^{2}$ \\ From the Laboratory of Chemical Neurobiology, Department of Psychiatry, \\ McGill University, Montreal, Quebec, Canada
}

SYNOPSIS Concentrations of homovanillic acid (HVA) and 5-hydroxyindoleacetic acid (5-HIAA) were significantly higher in CSF obtained after injection of air during pneumoencephalography $?$ (PEG) than in lumbar CSF, as drawn before the injection. There was a high correlation between $\vec{\omega}$ levels in the 'mixed' and lumbar samples of CSF in the case of each of the two acids. The concentra-s tion of lumbar HVA, but not that of 5-HIAA, was negatively correlated with CSF pressure. 5-HIAA levels were low in both samples of CSF in a group of epileptics, by comparison with controls. In two patients with Kufs disease and in one with Niemann-Pick disease, the concentration of HVA was. very low in the lumbar sample. The application of a standardized PEG technique in the study of monoamine metabolism in man is suggested.

After the demonstration of 5-hydroxyindoleacetic acid (5-HIAA) (Ashcroft and Sharman, 1960) and homovanillic acid (HVA) (Andén et al., 1963) in human cerebrospinal fluid (CSF), an increasing number of reports on the CSF levels of these acidic metabolites of monoamines has been appearing in the literature. In some of these studies ventricular fluid obtained during diagnostic or therapeutic surgery has been used. This work has provided useful information on the cerebral roles of the two amines as detected by significant variation from control levels of the concentrations of their respective metabolites in several diseases, mainly neurological (Ashcroft and Sharman, 1960; Guldberg et al., 1967; Anderson and Roos, 1969; Papeschi et al., 1972). Information on the effects of drugs has also been obtained (Papeschi et al., 1972).

In most studies, however, particularly those concerned with psychiatric patients, investiga-

1 Research Trainee of the World Health Organization. Present address: Athens University, 74 Vas. Sophias Avenue, Athens, Greece.

${ }^{2}$ Address for reprints: Dr. T. L. Sourkes, Allan Memorial Institute of Psychiatry, 1025 Pine Avenue West, Montreal 112, Quebec, Canada. tors have reported results with lumbar CSF and $c$ have assumed that the concentrations of the metabolites in this fluid provide some indication $\vec{\theta}$ of brain monoamine metabolism. This approact does not take into account the substantial evi- dence that now exists that a significant portion of lumbar 5-HIAA comes from the spinal cord, whereas HVA seems to originate only in the brain (Bulat and Zivcovic, 1971; Curzon et al., $\stackrel{\circ}{\circ}$ 1971; Garelis and Sourkes, 1973; Post et al., $\overrightarrow{\vec{O}}$ 1973; Weir et al., 1973). Other factors that might $\Xi$ well influence lumbar concentrations of both 5-HIAA and HVA include the effect of mixing of CSF from different compartments, the possible role of hydrostatic pressure; the state of the CSF compartments - that is, whether the ventricles have undergone enlargement or narrowing; and whether there is restriction of flow of the CSF.

The present work was initiated as an attempt $\stackrel{\text { ? }}{?}$ to study the effect of these factors on the levels and distribution of the acidic metabolites in the CSF. The pneumoencephalography (PEG) tech-. nique was selected for this work because it can $\tilde{N}$ provide information on all the parameters men- $\underset{\mathbb{N}}{\mathrm{N}}$ tioned. It was also expected that additional $\underset{2}{2}$ 
information on the concentration of these metabolites in a variety of neuropsychiatric diseases would be obtained.

\section{METHODS}

Thirty-five patients undergoing diagnostic PEG at the Montreal Neurological Hospital were included in this study, without previous selection. During this work, lumbar CSF from two cases with Kufs disease became available and the results are reported here. Patients with evidence of obstruction of CSF flow were excluded from this series; those results have been reported separately (Garelis and Sourkes, 1973).

After the evening meal patients did not have any food until the procedure had been completed on the following day (generally before noon). One-half to one hour before PEG was started preparatory medication was given. In most cases this consisted of codeine $60 \mathrm{mg}$, dimenhydrinate (Gravol) $50 \mathrm{mg}$, and diazepam (Valium) $10 \mathrm{mg}$, intramuscularly. Occasionally, sodium pentobarbitone $(100 \mathrm{mg})$ was substituted for diazepam.

After the lumbar puncture had been performed, CSF pressure was recorded in the sitting position. For routine diagnostic purposes 3-4 ml of fluid were kept, then the first sample ('lumbar') for this study was collected. At this time, air was fractionally injected through the puncture needle, and CSF was collected through the needle. At the end of the procedure, when all the air had been injected, the second ('mixed') specimen was taken. Samples were rapidly frozen and kept at $-20^{\circ} \mathrm{C}$ until analysed.

HVA and 5-HIAA were measured fluorimetrically in the same sample, as described by Papeschi and

TABLE 1

HVA AND 5-HIAA CONCENTRATIONS (NG/ML) IN LUMBAR AND MIXED SAMPLES OF PATIENTS UNDERGOING PNEUMOENCEPHALOGRAPHY

\begin{tabular}{|c|c|c|c|c|c|c|c|c|}
\hline \multirow{2}{*}{\multicolumn{3}{|c|}{ Diagnosis }} & \multicolumn{3}{|c|}{$H V A$} & \multicolumn{3}{|c|}{ 5-HIAA } \\
\hline & & & Lumbar & \multicolumn{2}{|c|}{ Mixed } & Lumbar & \multicolumn{2}{|c|}{ Mixed } \\
\hline \multicolumn{2}{|c|}{$\begin{array}{l}\text { Controls } \\
\text { Epilepsy } \\
\text { Brain-stem encephalopathy } \\
\text { Kufs disease } \\
\text { Kufs disease } \\
\text { Niemann-Pick variant } \\
\text { Possible Parkinsonism } \\
\text { Schizophrenia }\end{array}$} & & $\begin{array}{l}43 \cdot 1 \pm 3 \cdot 5(10) \\
42 \cdot 8 \pm 4 \cdot 5(12) \\
32 \cdot 25 \pm 8 \cdot 4(4) \\
\text { Undetectable } \\
\text { Undetectable } \\
13 \\
36 \\
-\end{array}$ & $\begin{array}{l}65 \cdot 9 \pm 6 \\
60 \cdot 5 \pm 6 \cdot 9 \\
37 \cdot 5 \pm 8 \cdot 7 \\
- \\
- \\
76 \\
62 \\
153\end{array}$ & $\begin{array}{l}\text { 1)* } \\
\text { 12) } \\
4\end{array}$ & $\begin{array}{l}32 \cdot 1 \pm 2 \cdot 4(16) \\
24 \cdot 6 \pm 2(12) \ddagger \\
34 \cdot 7 \pm 1 \cdot 9(4) \\
35\end{array}$ & $\begin{array}{l}44 \\
32 \\
34 \\
- \\
- \\
\\
41 \\
90\end{array}$ & $\begin{array}{l} \pm 4 \cdot 8(16) \dagger \\
\pm 5 \cdot 1(12) \\
\pm 3 \cdot 11(4)\end{array}$ \\
\hline \multicolumn{3}{|c|}{ * Different from lumbar at $\mathrm{P}<0.005$. } & $\begin{array}{l}\text { Mean } \pm \text { SE (nu } \\
\dagger \text { Different fron }\end{array}$ & $\begin{array}{l}\text { er of meas } \\
\text { umbar at } P\end{array}$ & $\begin{array}{l}\text { ments) } \\
0.025\end{array}$ & \multicolumn{3}{|c|}{$\ddagger$ Different from controls at $\mathrm{P}<0.025$. } \\
\hline \multirow{2}{*}{\multicolumn{9}{|c|}{ CONCENTRATIONS OF HVA AND 5-HIAA (NG/ML) IN LUMBAR AND MIXED FLUIDS OF EPILEPTIC PATIENTS }} \\
\hline & & & & & & & & \\
\hline \multirow{2}{*}{$\begin{array}{c}\text { Age, sex } \\
(y r)\end{array}$} & \multirow{2}{*}{$\begin{array}{l}\text { Type of } \\
\text { seizure }\end{array}$} & \multirow{2}{*}{\multicolumn{2}{|c|}{$\begin{array}{c}\text { Drug* } \\
\text { (mg/day) }\end{array}$}} & & \multicolumn{2}{|c|}{$H V A$} & \multicolumn{2}{|c|}{ 5-HIAA } \\
\hline & & & & & Lumbar & Mixed & Lumbar & Mixed \\
\hline $18 \mathrm{~F}$ & Temporal & \multirow{5}{*}{\multicolumn{3}{|c|}{$\begin{array}{l}\text { Phenytoin } 200 \text {, phenobarbitone } 60 \\
\text { Primidone } 200 \text {, ethosuximide } 750 \\
\text { Methylphenobarbitone } 300 \\
\text { Phenobarbitone } 120 \text {, chloral } 500 \\
\text { Phenobarbitone } 120\end{array}$}} & 69 & 111 & 25 & 38 \\
\hline $22 \mathrm{~F}$ & Temporal & & & & 44 & 44 & 23 & 8 \\
\hline $22 \mathrm{M}$ & Temporal & & & & 41 & 45 & 34 & 36 \\
\hline $21 \mathrm{M}$ & Temporal & & & & 26 & 50 & 32 & 36 \\
\hline $52 \mathrm{M}$ & Temporal & & & & 50 & 82 & 16 & 36 \\
\hline $39 \mathrm{M}$ & Temporal & \multicolumn{3}{|c|}{ - } & 36 & 41 & 18 & 21 \\
\hline $62 \mathrm{M}$ & Temporal & \multicolumn{3}{|c|}{-} & 50 & 56 & 29 & 45 \\
\hline $15 \mathrm{M}$ & Corticoreticular & \multicolumn{3}{|c|}{ Primidone 750} & 31 & 51 & 33 & 82 \\
\hline $18 \mathrm{M}$ & Temporal- & Pher & ytoin 300 , phenob & itone 90 & 43 & 88 & 13 & 34 \\
\hline $50 \mathrm{~F}$ & $\begin{array}{l}\text { grand mal } \\
\text { Grand mal } \\
\text { (withdrawal?) }\end{array}$ & Pher & $\begin{array}{l}\text { ytoin } 300, \text { phenob } \\
\text { midone } 750\end{array}$ & itone 30 & 72 & 81 & 23 & 28 \\
\hline $39 \mathrm{M}$ & Grand mal & Pher & $\begin{array}{l}\text { obarbitone } 30, \\
\text { osuximide } 1000\end{array}$ & & 27 & 44 & 28 & 33 \\
\hline $26 \mathrm{~F}$ & Grand mal & Pher & obarbitone 240 & & 25 & 33 & 21 & 22 \\
\hline
\end{tabular}


McClure (1971). Clinical information and PEG findings were always obtained after the biochemical determinations had been performed.

For statistical analysis, subjects were grouped according to diagnostic category. Criteria for the selection of controls were: (1) absence of any disease where changes in serotonin or dopamine metabolism have been implicated, and (2) non-use of medication known to affect monoamine metabolism-for example, sedatives, neuroleptics. The diagnoses in the control group included the following: headache, facial pain, hysterical neurosis, spastic hemiparesis, optic atrophy, arterial aneurysm, chromophobe adenoma.

\section{RESULTS}

HVA and 5-HIAA concentrations in the lumbar and mixed samples are shown in Table 1 along with clinical diagnoses.

Acid levels of the control group were significantly higher in the mixed than in the lumbar specimen. This was also true for all other subjects, with the exception of cases of brain-stem encephalopathy (BSE).

The epileptic patients had HVA concentrations in their CSF samples similar to control values. On the other hand, 5-HIAA was lower in both lumbar and mixed fluid than in the

TABLE 3

CORRELATIONS BETWEEN MEASURED VARIABLES

\begin{tabular}{|c|c|c|c|c|}
\hline Variables & Subjects & $N$ & $R$ & $P^{*}$ \\
\hline $\begin{array}{l}\text { HVA vs 5-HIAA, in lumbar } \\
\text { CSF }\end{array}$ & $\begin{array}{l}\text { Controls } \\
\text { Epilepsy } \\
\text { BSE† } \dagger\end{array}$ & $\begin{array}{r}10 \\
12 \\
4\end{array}$ & $\begin{array}{l}0 \cdot 771 \\
0 \cdot 238 \\
0 \cdot 840\end{array}$ & $\begin{array}{l}<0.005 \\
\text { NS } \\
\text { NS }\end{array}$ \\
\hline $\begin{array}{l}\text { HVA vs 5-HIAA, in mixed } \\
\text { CSF }\end{array}$ & $\begin{array}{l}\text { Controls } \\
\text { Epilepsy } \\
\text { BSE }\end{array}$ & $\begin{array}{r}11 \\
12 \\
4\end{array}$ & $\begin{array}{l}0 \cdot 767 \\
0 \cdot 126 \\
0 \cdot 679\end{array}$ & $\begin{array}{l}<0.005 \\
\text { NS } \\
\text { NS }\end{array}$ \\
\hline $\begin{array}{l}\text { Lumbar HVA vs CSF } \\
\text { pressure }\end{array}$ & All cases $\ddagger$ & 26 & -0.474 & $<0.02$ \\
\hline $\begin{array}{l}\text { Lumbar 5-HIAA vs CSF } \\
\text { pressure }\end{array}$ & All cases & 32 & 0.21 & NS \\
\hline $\begin{array}{l}\text { HVA in mixed CSF vs total } \\
\text { volume of injected air } \\
\text { (range }=40-125 \mathrm{ml})\end{array}$ & $\begin{array}{l}\text { Controls } \\
\text { Epilepsy }\end{array}$ & $\begin{array}{l}11 \\
12\end{array}$ & $\begin{array}{l}-0.234 \\
-0.088\end{array}$ & $\begin{array}{l}\text { NS } \\
\text { NS }\end{array}$ \\
\hline $\begin{array}{l}\text { 5-HIAA in mixed CSF vs total } \\
\text { volume of injected air }\end{array}$ & $\begin{array}{l}\text { Controls } \\
\text { Epilepsy }\end{array}$ & $\begin{array}{l}16 \\
12\end{array}$ & $\begin{array}{r}0 \cdot 223 \\
-0 \cdot 134\end{array}$ & $\begin{array}{l}\text { NS } \\
\text { NS }\end{array}$ \\
\hline $\begin{array}{l}\text { HVA in mixed CSF vs total } \\
\text { volume of CSF withdrawn } \\
\text { (range }=25-65 \mathrm{ml} \text { ) }\end{array}$ & $\begin{array}{l}\text { Controls } \\
\text { Epilepsy }\end{array}$ & $\begin{array}{l}11 \\
12\end{array}$ & $\begin{array}{l}0.363 \\
0.419\end{array}$ & $\begin{array}{l}\text { NS } \\
\text { NS }\end{array}$ \\
\hline $\begin{array}{l}\text { 5-HIAA in mixed CSF vs total } \\
\text { volume of CSF }\end{array}$ & $\begin{array}{l}\text { Controls } \\
\text { Epilepsy }\end{array}$ & $\begin{array}{l}16 \\
12\end{array}$ & $\begin{array}{l}0 \cdot 216 \\
0.600\end{array}$ & $\begin{array}{l}\text { NS } \\
<0.05\end{array}$ \\
\hline
\end{tabular}

* Probabilities. NS represents $P>0.05$.

+ BSE = Brain-stem encephalopathy.

$\ddagger$ All cases are pooled where compared variables did not differ significantly. corresponding control samples; this difference reached statistical significance in the lumbar CSF (Table 1). The data for the epileptic patients including clinical information, are set out ix Table 2.

No HVA could be detected in the lumbar CSF of the two siblings with Kufs disease. HVA was also low in the first sample of the patient with Niemann-Pick disease, but normal in the mixed: one. One patient possibly suffering from Parkinsonism had normal concentrations of botte acids. A schizophrenic subject had very high HVA and 5HIAA in the mixed CSF, but low 5-HIAA in the lumbar sample.

Correlation coefficients between pairs of thes investigated variables were calculated and arẹ shown in Table 3. Concentrations of the acids were highly correlated in both the lumbar and the mixed specimens in the control group, but not in the patients with epilepsy or BSE. The correlation between the metabolite concentra tions in the lumbar CSF of our controls wasan close agreement with data obtained in healti volunteers (Gottfries et al., 1971). There waspa significant negative correlation between C\&F pressure and lumbar HVA but not 5-HIAA.

Because of the gradient of concentrations metabolites, higher values being found in upper CSF compartments (Table 1; Garelis a a Sourkes, 1973), the amount of injected air or the total volume of withdrawn CSF might yield as positive correlation with the concentration of the metabolites in the mixed sample. However, the present data provided no basis for such correla $\frac{\mathbb{D}}{2}$ tions (Table 3).

\section{DISCUSSION}

It has been suggested that the injection of aip during PEG results in concentrations of metabol? ites that would reflect ventricular rather than lumbar levels (Moir et al., 1970). This would be due to mixing of CSF of various compartments by the ascending air, and to disturbance of the normal gradient from the lateral ventricle through the cisterna magna to the lumbar levelo Few investigations have taken advantage of PEG to study physiological or clinical relationships of monoamine metabolites. There is only one study directly comparing concentrations of 5-HIAA before and after the injection of air ip 
three patients; the concentration of 5-HIAA in the mixed sample was approximately double the lumbar level (Eccleston et al., 1970). In two more reports from the same group, similar values for 5-HIAA were found in the mixed sample, but lumbar fluid was not taken (Ashcroft and Sharman, 1960; Ashcroft et al., 1966).

In our control group, concentrations of 5-HIAA in both samples were higher than those reported by the Edinburgh investigators. The mixed/lumbar ratio for 5-HIAA however, was substantially smaller in our case. Several methodological differences might account for this discrepancy. The amount of air injected and the volume of CSF withdrawn were much greater in the present study. The injection of large amounts of air, much of which was directed to subarachnoid space outside the ventricles, coupled with the withdrawal of a large volume of CSF and the ensuing drastic changes in hydrostatic pressure would result in a downward current of fluid not only from the ventricles, but also from the subarachnoid space surrounding the brain. Concentrations of the metabolites in the latter space were not known, but might be relatively low, inasmuch as transport of the acids from the central nervous system is located mainly in the choroid plexuses (Ashcroft et al., 1968; Cserr and Van Dyke, 1971; Forn, 1972). Thus, the mixing process affects compartments with different mean concentrations of the metabolites, and is itself affected by the volume of air injected and fluid displaced. The lack of significant correlation between these two variables on the one hand, and acid concentrations in the mixed samples on the other (Table 3), was not surprising.

Another factor which could explain our failure to obtain the high concentrations of metabolites characteristic of the ventricular and cisternal compartments in the mixed samples was the effect of premedication. The patients in the study of Ashcroft et al. (1966) received only paracetamol orally, whereas all our patients had had heavy preparatory medication (see Methods section). Antihistamines (Coyle and Snyder, 1969), barbiturates (Corrodi et al., 1966, 1967), and benzodiazepines (Corrodi et al., 1967; Taylor and Laverty, 1969; Chase et al., 1970; Wise et al., 1972; Papeschi et al., 1972) are known to influence monoamine metabolism.
Pharmacologically induced changes in serotonin or dopamine metabolism are evident in the cisternal 5-HIAA (Andersson and Roos, 1968; Eccleston et al., 1968) and HVA (Pletscher et al., 1967) in about one hour, but much later in the lumbar fluid. The interval between injection of premedication and collection of the mixed sample in the present study was 1-1.5 hours and less than one hour for the lumbar specimen. Under these conditions, therefore, premedication would affect the mixed, but not the lumbar sample.

Moreover, a possible effect of these drugs on the transport mechanisms and local hydrostatic pressure cannot be excluded. It would be difficult to predict, from the available data, what the net effect of the drug combinations used in this study on the acid levels in CSF would be.

The somewhat sharper gradient for HVA than 5-HIAA on going from the mixed sample to the lumbar CSF (Table 1) could be accounted for by the fact that 5-HIAA, but not HVA, in the CSF originates to a substantial extent from the spinal cord (Garelis and Sourkes, 1973; Young et al., 1973); consequently, mixing during PEG would disturb the 5-HIAA gradient less than that of HVA.

Low ventricular (Papeschi et al., 1972) and lumbar concentrations of HVA (Bernheimer $e t$ al., 1966; Barolin and Hornykiewicz, 1967) have been reported in some epileptic patients. This was not the case in our series in either the mixed or the lumbar sample. It is difficult to account for the apparent discrepancy in regard to HVA. However, it should be recalled that half the patients in the series of Barolin and Hornykiewicz (1967), mainly tumour epilepsies, had normal values.

In contrast with the result with HVA, low 5-HIAA levels were found in both specimens; the difference from controls reached significance for the lumbar fluid (Table 1). In the recent study from this laboratory (Papeschi et al., 1972), three cases of temporal lobe epilepsy had low ventricular 5-HIAA. This finding could not be further evaluated at the time for lack of adequate controls, but the concentrations were much lower than reported ventricular, or even normal cisternal, levels (Moir et al., 1970; Garelis and Sourkes, 1973). Moreover, preliminary results obtained by Shaywitz et al. (1973) showed a 
decreased accumulation of 5-HIAA after probenecid in epilepsy.

Epilepsy is not a homogeneous disease. Grouping of all patients with convulsions, regardless of aetiology, localization of the lesion, type and frequency of seizures, or concomitant psychiatric symptoms, may obscure possible associations of the biogenic amines with convulsive disorders. More important, the effect of antiepileptic medication has scarcely been studied. Barolin and Hornykiewicz (1967) provided evidence that low lumbar HVA in some of their patients was not due to the effect of diphenylhydantoin. However, the effect of chronically administered combinations of anticonvulsants on CSF levels of monoamine metabolites is currently unknown. It can be seen from Table 2 that variations in the parameters mentioned above make practically each patient in our group different from the others.

We have no ready explanation for the absence of an increase of concentrations of the acids in the mixed fluid of the patients with BSE. Since most of the serotoninergic neurones are in the brain-stem it might be postulated that 5-HIAA would be low in the mixed sample because of destruction of these neurones. In the lumbar sample, this decrease could be compensated by a contribution from spinal interneurones (Post $e t$ al., 1973). This mechanism, however, should leave HVA unaffected. Some of these patients were probably suffering from multiple sclerosis, but this diagnosis was avoided in the absence of clear-cut recurrent episodes. Low concentrations of HVA and/or 5-HIAA in multiple sclerosis have recently been reported (Johansson et al., 1972).

The virtual absence of HVA in the two siblings with Kufs disease was an unexpected finding. Although these patients are known to manifest occasionally extrapyramidal symptoms (Sourkes, 1962), decreased dopamine metabolism has never, to the best of our knowledge, been implicated in any of the lipidoses. Our two patients did not have extrapyramidal symptoms.

The patient suffering from a variant of Niemann-Pick disease also had low HVA in the lumbar sample. But the high level in the mixed fluid suggested that reduced flow of the acid towards the lumbar space, rather than a deficiency in dopamine metabolism was responsible for the low lumbar levels. Although the present data are few in number, the results indicate the need for further studies of dopamine metabolism in the lipidoses.

The possibility of Parkinson's disease in the next patient (Table 1) was raised because of the presence of an obscure tremor of recent onset Notwithstanding the doubts about the diagnosis it was not surprising that HVA was normal inthis patient, for it has been shown (Papeschi $e$ ? al., 1972) that low HVA levels are particularlye correlated with akinesia; this was absent in the present patient.

Concentrations of both acids in the mixed ${ }^{2}$ fluid of the schizophrenic patient are the highest in the present series. Bowers (1969) has reported a case of schizoaffective psychosis with very high levels of both acids and provided evidence for $\omega$ defective transport mechanism in that case. This possibility can be excluded in our patien because in such a condition, lumbar 5-HIAA would also be high. Low concentrations of 5-HIAA in schizophrenia have been reportod (Ashcroft et al., 1966; Bowers et al., 1969) b bito other investigators were not able to confirm thes finding (Persson and Roos, 1969; Rimón et ă 1971).

The finding that the hydrostatic pressure the CSF is related to lumbar levels of HAA negatively may seem surprising, as it is known that high intracranial pressure (hydrocephalus) is associated with very high concentrations of both HVA and 5-HIAA. However, this is pres sumed to result from blockade of the transport mechanism (Andersson and Roos, 1968). In this study there were no cases with signs of hydro 3 cephalus; the pressure range was within normal? limits. Under these conditions, there is no question of an effect on the transport mechanism

Local hydrostatic pressure is known to affecto the flow of CSF (Davson, 1967). Most of or allo the lumbar HVA comes from higher levels via the cisterna magna (Curzon et al., 1971; Gareliso and Sourkes, 1973; Post et al., 1973). Changes in the cisterno-lumbar flow therefore, induced by local variations in pressure, would affect theo lumbar levels of HVA. On the other hand, a substantial proportion of 5-HIAA originates in the spinal cord (Garelis and Sourkes, 1973). Conse- N quently, small variations in CSF flow from the cisterna magna would affect the total lumbare 
concentrations to a far smaller extent. This could explain the absence of a significant effect of pressure on lumbar levels of 5-HIAA (Table 3).

One cannot exclude the possibility that higher pressures favour more rapid movement of water from the lumbar CSF compartment and bulk transport of solutes, like HVA, along with it.

On the question of the proportion of 5-HIAA originating in the spinal cord, our original estimate was based on controls selected only on the basis of absence of obstruction of CSF flow (Garelis and Sourkes, 1973). Using the much more refined present group of controls, 5-HIAA of spinal origin is estimated to account for $39 \%$ of the lumbar concentration. The recent paper by Weir et al. (1973) of a study in experimental animals reports a similar value.

The results of the present work show how one can take advantage of PEG as a very useful technique in the study of monoamine metabolism in man. In this study we deliberately avoided any attempt to standardize the conditions of obtaining samples because our aim was to study the effect of a range of different conditions. However, it is conceivable that injection of a small amount of air directed into the ventricles, followed by withdrawal of a small quantity of CSF under standardized conditions, could be effective in providing enough mixing to give a reliable indication of the concentrations of the acidic metabolites in the ventricular system, and thus to provide some reflection of amine metabolism in the brain. Under the above conditions premedication, clearly a disadvantage, would not be indispensable. Nor would the procedure be more distressing to the patients than the two lumbar punctures routinely employed in the probenecid technique of assessing the metabolite concentrations.

The importance of seeking new techniques needs to be stressed, as means of obtaining decisive information about the state and metabolism of biogenic amines in the healthy and ailing human brain during life. Information of this kind ought to help greatly in clarifying the role of these substances in important diseases where they have already been implicated: in schizophrenia, manic-depressive psychosis, and diseases of the basal ganglia.

The cooperation of Dr. W. Feindel, Montreal Neuro- logical Hospital, is gratefully recorded. This work was supported by a grant of the Medical Research Council (Canada) to T.L.S.

\section{REFERENCES}

Andén, N.-E., Roos, B.-E., and Werdinius, B. (1963). On the occurrence of homovanillic acid in brain and cerebrospinal fluid and its determination by a fluorometric method. Lif Sciences, 2, 448-458.

Andersson, H., and Roos, B.-E. (1968). The effect of probenecid on the elimination from CSF of intraventricularly injected 5-hydroxyindoleacetic acid in normal and hydrocephalic dogs. Journal of Pharmacy and Pharmacology, 20, 879-881.

Andersson, H., and Roos, B.-E. (1969). 5-Hydroxyindoleacetic acid in cerebrospinal fluid of hydrocephalic children. Acta Pediatrica Scandinavica, 58, 601-608.

Ashcroft, G. W., and Sharman, D. F. (1960). 5-Hydroxyindoles in human cerebrospinal fluids. Nature, 182, 1050 1051.

Ashcroft, G. W., Crawford, T. B. B., Eccleston, D., Sharman, D. F., MacDougall, E. J., Stanton, J. B., and Binns, J. K. (1966). 5-Hydroxyindole compounds in the cerebrospinal fluid of patients with psychiatric or neurological diseases. Lancet, 2, 1049-1052.

Ashcroft, G. W., Dow, R. C., and Moir, A. T. B. (1968). The active transport of 5-hydroxyindol-3-ylacetic acid and 3-methoxy-4-hydroxyphenylacetic acid from a recirculatory perfusion system of the cerebral ventricles of the unanaesthetized dog. Journal of Physiology, 199, 397-425.

Barolin, G. S., and Hornykiewicz, O. (1967). Zur diagnostischen Wertigkeit der Homovanillinsäure im Liquor cerebrospinalis. Wiener klinische Wochenschrift, 79, 815818.

Bernheimer, H., Birkmayer, W., and Hornykiewicz, O. (1966). Homovanillinsäure im Liquor cerebrospinalis: Untersuchungen beim Parkinson-Syndrom und anderen Erkrankungen des ZNS. Wiener klinische Wochenschrift, 78, 417-419.

Bowers, M. B., Jr. (1969). Deficient transport mechanism for the removal of acid monoamine metabolites from cerebrospinal fluid. Brain Research, 15, 522-524.

Bowers, M. B., Jr., Heninger, G. R., and Gerbode, F. (1969). Cerebrospinal fluid 5-hydroxyindoleacetic acid and homovanillic acid in psychiatric patients. International Journal of Neuropharmacology, 8, 255-262.

Bulat, M., and Živković, B. (1971). Origin of 5-hydroxyindoleacetic acid in the spinal fluid. Science, 173, 738-740.

Chase, T. N., Katz, R. I., and Kopin, I. J. (1970). Effect of diazepam on fate of intracisternally injected serotonin- $\mathrm{C}^{14}$. Neuropharmacology, 9, 103-108.

Corrodi, H., Fuxe, K., and Hökfelt, T. (1966). The effects of barbiturates on the activity of the catecholamine neurones in the rat brain. Journal of Pharmacy and Pharmacology, 18, 556-558.

Corrodi, H., Fuxe, K., and Hökfelt, T. (1967). The effect of some psychoactive drugs on central monoamine neurons. European Journal of Pharmacology, 1, 363-368.

Coyle, J. T., and Snyder, S. H. (1969). Antiparkinsonian drugs: inhibition of dopamine uptake in the corpus striatum as a possible mechanism of action. Science, 166, 889-901.

Cserr, H. F., and Dyke, D. H. van (1971). 5-Hydroxyindoleacetic acid accumulation by isolated choroid plexus. American Journal of Physiology, 220, 718-723. 
Curzon, G., Gumpert, E. J. W., and Sharpe, D. M. (1971). Amine metabolites in the lumbar cerebrospinal fluid of humans with restricted flow of cerebrospinal fluid. Nature, New Biology, 231, 189-191.

Davson, H. (1967). The Physiology of the Cerebrospinal Fluid. Churchill: London.

Eccleston, D., Ashcroft, G. W., Crawford, T. B. B., Stanton, J. B., Wood, D., and McTurk, P. H. (1970). Effect of tryptophan administration on 5HIAA in cerebrospinal fluid in man. Journal of Neurology, Neurosurgery, and Psychiatry, 33, 269-272.

Eccleston, D., Ashcroft, G. W., Moir, A. T. B., ParkerRhodes, A., Lutz, W., O'Mahoney, D. P. (1968). A comparison of 5-hydroxyindoles in various regions of dog brain and cerebrospinal fluid. Journal of Neurochemistry, 15, 947-957.

Forn, J. (1972). Active transport of 5-hydroxyindoleacetic acid by the rabbit choroid plexus in vitro. Blockade by probenecid and metabolic inhibitors. Biochemical Pharmacology, 21, 619-624.

Garelis, E., and Sourkes, T. L. (1973). Sites of origin in the central nervous system of monoamine metabolites measured in human cerebrospinal fluid. Journal of Neurology, Neurosurgery, and Psychiatry, 36, 625-629.

Gottfries, C. G., Gottfries, I., Johansson, B., Olsson, R., Persson, T., Roos, B.-E., and Sjöström, R. (1971). Acid monoamine metabolites in human cerebrospinal fluid and their relations to age and sex. Neuropharmacology, 10, 665672.

Guldberg, H. C., Turner, J. W., Hanieh, A., Ashcroft, G. W., Crawford, T. B. B., Perry, W. L. M., and Gillingham, F. J. (1967). On the occurrence of homovanillic acid and 5hydroxyindol-3-ylacetic acid in the ventricular CSF of patients suffering from parkinsonism. Confinia Neurologica, 29, 73-77.

Johansson, B., Roos, B.-E., and Wålinder, J. (1972). 5-HIAA and HVA in cerebrospinal fluid during delirium acutum. New England Journal of Medicine, 286, 1160-1161.

Moir, A. T. B., Ashcroft, G. W., Crawford, T. B. B., Eccleston, D., and Guldberg, H. C. (1970). Cerebral metabolites in cerebrospinal fluid as a biochemical approach to the brain. Brain, 93, 357-368.

Papeschi, R., and McClure, D. J. (1971). Homovanillic and 5 -hydroxyindoleacetic acid in cerebrospinal fluid of de- pressed patients. Archives of General Psychiatry, 25, 354 358.

Papeschi, R., Molina-Negro, P., Sourkes, T. L., and Erba, (1972). The concentration of homovanillic and 5-hydrox $\bar{B}$ indoleacetic acids in ventricular and lumbar $\mathrm{CSF}_{\mathrm{F}}$ Neurology (Minneap.), 22, 1151-1159.

Persson, T., and Roos, B.-E. (1969). Acid metabolites from monoamines in cerebrospinal fluid of chronic schizo. phrenics. British Journal of Psychiatry, 115, 95-98.

Pletscher, A., Bartholini, G., and Tissot, R. (1967). Metabolie fate of $\mathrm{L}-\left[{ }^{14} \mathrm{C}\right]$ DOPA in cerebrospinal fluid and blood plasma of humans. Brain Research, 4, 106-109.

Post, R. M., Goodwin, F. K., Gordon, E., and Watki D. M. (1973). Amine metabolites in human cerebrosping fluid: effects of cord transection and spinal fluid bloc Science, 179, 897-899.

Rimón, R., Roos, B.-E., Räkköläinen, V., and Alanen, (1971). The content of 5-hydroxyindoleacetic acid and homovanillic acid in the cerebrospinal fluid of patients with acute schizophrenia. Journal of Psychosomatic Research, 15, 375-378.

Shaywitz, B. A., Cohen, D. J., and Bowers, M. B., Jr. (1973) Brain monoamine turnover in children: preliminan results in epilepsy, minimal brain dysfunction, and move ment disorders. (Abstract.) Neurology (Minneap.), 23 428-429.

Sourkes, T. L. (1962). Biochemistry of Mental Diseas Harper and Row: New York.

Taylor, K. M., and Laverty, R. (1969). The effect of cló. diazepoxide, diazepam and nitrazepam on catecholaripine metabolism in regions of the rat brain. European Journof of Pharmacology, 8, 296-301.

Weir, R. L., Chase, T. N., Ng, L. K. Y., and Kopin, Ф (1973). 5-Hydroxyindoleacetic acid in spinal fluid: relafice contribution from brain and spinal cord. Brain Rese@c 52, 409-412.

Wise, C. D., Berger, B. D., and Stein, L. (1972). Benzodifze pines: anxiety-reducing activity by reduction of serotoni turnover in the brain. Science, 177, 180-183.

Young, S. N., Lal, S., Martin, J. B., Ford, R. M., an Sourkes, T. L. (1974). 5-Hydroxyindoleacetic acid, homos vanillic acid and tryptophan levels in CSF above an $\Phi$ below a complete block of CSF flow. Psychiatria, Neurg logia, et Neurochirurgia. (In press.) 